\title{
Resilience in Quaking Aspen: recent advances and future needs
}

\author{
*Corresponding Author: Paul C. Rogers \\ Western Aspen Alliance, Ecology Center, and Wildland Resources Department \\ Utah State University, Logan, Utah, USA \\ Ph: (435)797-0194 \\ email: p.rogers@usu.edu
}

1

2

\section{Cristina Eisenberg}

Department of Forest Ecosystems and Society, College of Forestry

Oregon State University, Corvalis, Oregon, USA

Ph: 406-270-5153

email: Cristina.eisenberg@oregonstate.edu \section{(1)}

\section{Samuel B. St. Clair}

Department of Plant and Wildlife Sciences, Brigham Young University, Provo, Utah, USA

Ph: 801-422-5725

email: stclair@byu.edu 
25 Abstract

Quaking aspen (Populus tremuloides) sustainability is a topic of intense interest in forest ecology.

Reports range from declines to persisting or increasing coverage in some areas. Moreover, there is little agreement on ultimate factors driving changes. Low aspen recruitment has been attributed to climate patterns, past management, herbivore increases, competitive interactions with conifers, predator and 31 beaver extirpation, and livestock grazing. Several of these potential causes result from direct or indirect

32 actions of human agency. On June 27-28, 2012 a group of leading aspen ecologists from diverse

33 backgrounds convened at the High Lonesome Ranch in western Colorado to address the state of aspen

34 science under the title, Resilience in Quaking Aspen: restoring ecosystem processes through applied

35 science. The purposes of this meeting were to: a) present disciplinary updates on recent developments; $b$ )

36 focus our collective understanding on determining key research gaps; and, to the extent possible, c)

37 develop a plan to communicate both advances and science gaps to wider audiences. Presentations and group discussions were framed mainly in the geographic context of the western U.S. The symposium addressed dual central themes_-historical aspen cover change and ungulate herbivory—both of which have important ramifications for future aspen resilience. We also found emergent themes in disturbance,

41 climate work, and genetic innovation. This paper presents a brief review of the state of aspen science and 42 a synopsis of issues and needs identified at the symposium. Detailed treatments of topics mentioned here 43 are found in accompanying articles of this volume. A key recommendation from researchers here is that 44 there are many "aspen types" and novel, landscape- or aspen type-specific, approaches will be required to 45 appropriately address this regional diversity. We further emphasize needed interdisciplinary work 46 addressing changing climates, altered disturbance patterns, intensive herbivory, and human drivers of 47 ecological change.

49 Keywords: cover change, Populus tremuloides, herbivory, climate, genetics, social science 


\section{Introduction}

Quaking Aspen (Populus tremuloides) provides local diversity, regional links in conservation corridors, and is North America's most widespread forest type. Its successful establishment across diverse landscapes and environmental extremes demonstrates adaptability as a species. However, reports of aspen decline suggest that changing ecological conditions and current management strategies may impose constraints on aspen resilience in portions of its range. In contrast, other studies describe areas in which aspen is persisting or expanding its range. We define aspen resilience as a condition wherein aspen can be sustained within its natural range of variation over time and space. Judicious intervention may be required to restore system resiliency where human actions have disrupted aspen functionality. Such efforts will involve intimate knowledge of forest dynamics, as the conditions that influence the sustainability

63 and function of aspen ecosystems are complex. Additionally, humans have substantial influences on these processes, although little effort has been devoted to our society's aesthetic, cultural, and economic relationships with aspen and how they, indirectly, impact these systems. Ultimately, we need to know what value aspen ecosystems hold in our society and what the costs and benefits of sustaining them will be. The central goals of this Special Issue of Forest Ecology and Management are to identify aspen research advances for contemporary management applications and to highlight future avenues of study supporting system resilience. 
2

analysis, computing capacity, and modeling approaches). We hope this Special Issue serves as a state-of-the-science compendium, but also catalyzes deeper exploration and innovation on several fronts surrounding contemporary aspen ecology and management.

On June 27-28, 2012 we assembled a group of aspen researchers in western Colorado to address resilience in aspen forests. Synthesis talks and group discussions were focused on the following topics: aspen functional types; long-term cover change; fire ecology; mountain pine beetle-aspen interactions; chemical defenses; ungulate herbivory; trophic cascades; facilitation and competition; mortality and climate effects; genetic advances; and human dimensions. All but the first and last of these topic areas are covered in more detail by individual papers of this volume. We present this Special Issue for the purpose of providing broader perspectives on research advances and to identify key knowledge gaps requiring investigation in the field of aspen ecology. The purpose of this overview is to update readers on recent developments within our focal themes of long-term cover change and herbivory in aspen, while also introducing the emergent topics of climate and genetic factors that affect these communities.

\section{Themes in Applied Aspen Research}

\subsection{Long-term dynamics and cover change}

3

Popular media often present us with sensational descriptions of change in aspen forests, likely due to the iconic nature of this species. However, scientists commonly offer more nuanced, empirical explanations for such phenomena.. Change in the status of any species is difficult to fully understand without historical context (e.g., past burning, grazing, management, climate). Aspen forests are no different, although our tools for determining historical conditions continue to expand and improve. 
Nonetheless, numerous studies addressing aspen cover change have not produced a single conclusion:

99 differing results often reflect varying ecological conditions. However, methods and scales of study may

100 play a role in these disparate findings. Taken individually these studies provide diverse perspectives on

101 aspen community dynamics and resilience. Collectively they illuminate the complexity of aspen ecology

102 and conservation status.

103 Despite a century of interest in measuring aspen forests, we cannot definitely say if aspen across

104 any given region is expanding or contracting. While some authors have reported 20th century decline

105 (DiOrio et al., 2004; Gallant et al., 2003; Bartos and Campbell, 1998), others have documented marked

106 expansions (Kulakowski et al., 2004; Manier and Laven, 2002), and still others have shown both

107 expansions and contractions in the same area (Brown et al., 2006; Sankey, 2009). Undoubtedly,

108 variations in site conditions, as well as lack of standard terminology in defining change contribute to

109 these different findings. For example, it is difficult to know where true change occurs when historical

110 sources may have used vastly different methods to define dominant cover. Additionally, we acknowledge

111 that aspen forests differ across their broad range. Accordingly, across their expanse, aspen may be

112 affected in varying ways by disturbance mechanisms, plant-plant interactions, climate, water availability,

113 soil resources, and other environmental factors. Rogers et al. (in review), provide further detail of this

114 "functional type" approach to aspen classification. Indeed, an overarching theme that emerged from this

115 symposium was the recognition of a multiple aspen type paradigm. This may be helpful in understanding

116 aspen ecology and appropriate management actions, but further complicates measuring cover change:

117 changing definitions and multiple aspen types make gross assessments difficult.

118 A diverse array of tools, explored more fully by Kulakowski et al. (this volume), may be used to

119 investigate long-term cover change in aspen and associated vegetation types. Because aspen are

120 relatively short-lived and prone to various heart rots, reliance on purely dendrochronological methods is

121 limiting. In order to overcome methodological limits, and subsequent reduced inference, multiple lines of

122 ecological and historical evidence are required to yield the best results in understanding aspen change.

123 Even with the best of cross-indexed approaches, however, differing results may be found within adjacent 
124 stands or landscapes (Zier and Baker 2006, Sankey 2009); these results may often be explained by

125 differing aspen types (i.e., functional processes) in close proximity. A takeaway lesson from these

126 deliberations is that diverse patterns of aspen change are common and thus, despite media reports to the

127 contrary, no single trajectory should be expected.

$128 \quad$ Further insight regarding aspen cover change depends on a deeper knowledge of widespread

129 disturbances in the Intermountain West. In seral situations, aspen is an early successional species

130 dependent on disturbance to regenerate existing stands or colonize new areas (e.g., Landh $\square$ usser et al.,

131 2010). Common disturbances in aspen systems, such as fire, insect and disease outbreaks, wind storms,

132 and avalanches, are widely thought to shape forests at large scales and over long periods. Specifically, we

133 explored individual impacts of mountain pine beetle and wildfire on varying aspen forests. Recent

134 outbreaks of beetles are thought to increase opportunity for aspen expansion, although mixed results have

135 been described (Pelz \& Smith, this volume). Aspen seedling establishment in beetle outbreak areas has

136 apparently not been addressed by the scientific literature to date. While success of aspen's vegetative

137 recruitment is highly dependent on pre-outbreak presence of mature ramets, other factors (e.g., competing

138 species, soil conditions, resource availability) may enhance or inhibit success.

139 Aspen are paradoxically resistant to burning, yet dependent on fire. This situation, if properly

140 understood, can inform appropriate use of prescribed and wildfire in aspen forests. We have long known

141 that fire rarely begins in aspen (e.g., Fechner and Barrows 1976), although after a fire starts, further

142 expansion will affect different aspen types to varying degrees. Wildfire occurrence in aspen depends on

143 competing and surrounding vegetation, as well as interactive effects of other disturbance agents on aspen

144 and cohort species. In general, wildfire affects stable aspen differently than seral stands. Introduction of a

145 new scheme delineating "aspen fire types" is presented here to assist practitioners in appropriate

146 understanding and use of fire in these forests (see Shinneman, this volume). We define "stable" aspen as

147 stands remaining in single-species dominance for long periods (i.e., at least 150 years), while the more

148 common seral aspen are subject to succession toward conifer dominance within a century. As a rule 
stable aspen are infrequently susceptible to stand-replacing events, including fire, whereas seral aspen are commonly vulnerable to catastrophic or mixed-severity fire.

A key research need in addressing the effects of disturbance on long-term cover change, including aspen fire ecology, is to determine historical range of variability (Landres et al. 1999) for various aspen conditions and sites. Site-specific historical range investigations will incorporate not only interactive effects of disturbances in aspen, but also use of modeling techniques to predict future impacts under altered climate scenarios. Until now, climate modeling efforts have taken a deterministic approach (Rehfeldt et al., 2010). To be effective, climate models addressing aspen cover change must incorporate elements driving both declines and expansions in a range of aspen types. For example, warming climates at many locations may limit aspen habitat, however where warming also includes frequent drought, there are many places where the resulting wildfires may contribute to aspen rejuvenation and even expansion (Zier and Baker, 2006).

\subsection{Ungulate herbivory}

Since the 1920s, impacts of wild and domestic herbivores on aspen have been a major concern in western North America. However, it is only within the last decade that ecologists have begun to achieve a more global understanding of how herbivory interacts with landscape-scale issues, such as aspen persistence, fire suppression, and climate disruption. Additionally, within the last decade scientists and managers are beginning to gain an understanding of how managing ungulates for "sustained yield" creates changes in aspen communities beyond the historical range of variability in these communities. In general, relatively short-lived aspen ramets depend on some level of continuous or episodic recruitment to persist. Where regenerating sprouts, or in some instances seedlings, are subjected to continuous browsing whole stands or landscapes may be threatened by a lack of "next generation" aspen to replace dying cohorts. In seral stands, aspen's facilitative role in conifer establishment and development (Calder and St.Clair 2012) could lead to modified forest structure or even loss of forest communities (St. Clair, this volume). There 
175 is also recognition that we need better knowledge of seasonal use and nutritional needs of ungulates (Beck

176 et al. 1996, Jones et al. 2009), and of the ecological impacts of wildlife management strategies that

177 include maintaining elevated ungulate populations in the absence of predation. This type of knowledge

178 may help ecologists not only address ungulate numbers, but perhaps influence seasonal movements to

179 minimize excessive damage to regenerating aspen. Before we make recommendations, however, we must

180 gain better understanding of environmental influences (e.g., predation risk, climate, nutrition, chemical

181 defense) controlling ungulate-aspen interactions.

182 Aspen, like many plants, employs a variety of strategies to deter excessive herbivory. Chemical

183 defense systems are used by plants to dissuade both insect and ungulate herbivory. While these effects

184 have long been known, new work on how aspen chemical defenses interact with environmental conditions

185 has advanced this science in the past decade. Of specific interest is the ability of aspen's chemical

186 defense mechanisms to repel or tolerate browsing by elk (Cervus edaphus) in the Rocky Mountain region

187 (Wooley et al. 2008). Work presented by Lindroth and St. Clair (this volume) explores not only tradeoffs

188 between growth and defense, but the precise role of phenolic glycosides in deterring browsers. Phenolic

189 glycoside concentrations found in aspen foliage are highly variable across landscapes depending on

190 genotype, tree age, light availability, and previous browse history. Chemical variability may explain

191 anecdotal observations of low, medium, and high levels of browse in adjacent aspen stands that may

192 easily be accessed by the same animals. Future investigations of spatial inconsistency of sucker survival

193 due to chemical ecology may provide further tools for land and wildlife managers in curtailing

194 overbrowsing, as well as educating the public.

195 Both wild and domestic browsers at high density, or in lower numbers for extended periods, can

196 disrupt ecosystem function. In addition to reducing or eliminating aspen recruitment, there are cascading

197 effects on aspen-dependent species (Martin \& Maron, 2012; Rogers et al. 2007). Seager and Eisenberg

198 (this volume) focus our attention more specifically on wild ungulates and the effects recent population

199 trends are having on aspen, but also how they are indirectly affecting aspen-dependent plants and animals.

200 Additionally, all ungulate populations at high density can compact soil, trample plants, and increase 
erosion; though moderate levels of browsing may actually increase plant diversity (Hobbs and Huenneke 1992). Historical context provides a critical piece of information in evaluating aspen resilience and its relationship to herbivory. For example, livestock were absent until the late $19^{\text {th }}$ century from most aspen communities in western North America, and large herbivore numbers were kept lower due to predation.

205 Thus, in exploring future management approaches, we are directed back toward enhancing our knowledge 206 of historical use and natural processes, which may be used proactively to regulate ungulate numbers and 207 movement for the benefit of aspen resilience.

208 Forest scientists often look to restoration of ecological function to guide successful management.

209 To the degree possible — frequently involving difficult social and political choices — managers should

210 allow multiple species interaction (i.e., contrast with select-species management) to influence stewardship

211 decisions. Where that is not possible, emulation of natural disturbance, climate impacts, predator-prey

212 relations, and other large- and small-scale processes may provide guidance for active and passive

213 restoration. In relation to native browsers, the cascading effects of top-down predators on ungulates are

214 thought to be a driving influence on aspen recruitment (Ripple et al. 2001). Eisenberg et al. (this volume)

215 review previous work placing it in the context of their ongoing studies of wolf (Canis lupus), elk, aspen

216 linkages in the Northern Rockies. Eisenberg et al. reveal varying levels of predator (i.e., process)

217 influence on ungulate-aspen systems. As with other aspects of aspen ecology, context plays a key role in

218 trophic cascades involving wolves, elk, and aspen, with effects such as fire, hunting of ungulates and

219 carnivores by humans, and climate moderating these relationships. The current body of trophic cascades

220 research indicates that recruitment of aspen ramets into the forest canopy is driven by multi-causal

221 factors. Once again, we arrive at the conclusion that we cannot neatly assign all aspen systems, or even

222 what are thought to be predominant influences, to one-size-fits-all paradigms. Future trophic cascades

223 research will involve examining how to functionally measure trophic interaction strength and direction in

224 an aspen system, thereby enabling manipulation of key elements (i.e., herbivore and apex predator

225 populations, disturbance regimes) to effectively restore impaired aspen communities. 
Climatic patterns play a large role in forest changes through time. Aspen forests have shown some sensitivity to climate extremes, particularly drought (Hogg et al., 2008). Today we have a far more

231 advanced awareness of the current and potential global impacts of climate change than we did even one

232 decade ago, but much work remains to be done. There is strong concern that expected climate warming,

233 and in some regions accompanying drought, will have deleterious effects on aspen persistence (Rehfeldt

234 et al. 2009). However, little work has been done to explore potential aspen range expansions, either via

235 vegetative or sexual regeneration, where new habitat for this species may arise. Some examples of past

236 expansions were noted where seedling habitat was created (Landh $\square$ usser et al., 2010) and where elevated

237 nitrogen emissions spurred forest expansion (Kochy and Wilson 2001). In contrast, Worrall et al. (this

238 volume) take a North American range-wide look at the role of drought and modeled the effect of climate

239 futures on aspen decline and mortality. This promising new work, in which they identify areas of both

240 weak and strong climatic effects on aspen and potential upslope migrations or expansions of suitable

241 aspen habitat in some mountainous regions, has the potential of helping us understand the impacts of

242 climate change on this species' range.

243 New areas for future work include climate modeling devoted to understanding resilience in aspen

244 (and many other species). This science is still in its infancy, with iterative improvements in this field

245 likely to follow. Other climate-atmospheric concerns, for instance direct impacts of carbon, nitrogen, and

246 ozone inputs, coupled with inclusion of disturbances and environmental variance within aspen

247 communities, may further complicate future modeling work. However, these elements are essential to

248 improving predictive ability in a resilience context.

A final consideration that may inform our understanding of aspen resilience is use of knowledge

250 and modeling of past climates to predict aspen responses to future climate scenarios. For example, can

251 long periods of historical drought (e.g., Medieval Warm Period) be used as analogues for future climate

252 conditions? If so, perhaps disturbance ecology dating methods, such as dendrochronology, charcoal 
dating, and pollen cores, can be used to estimate past conditions in order to provide model inputs for

254 future climate scenarios. While reliance on historical ecology may only provide partial solutions,

255 complementary efforts to restore key processes appear to hold the greatest promise for "managing for

256 resilience" in the face of climate uncertainty (Millar, et al., 2007)

\subsection{Aspen genetics}

Aspen's ecology and management is governed by its clonal nature. Rapid advances in genetic research are shedding new light on old assumptions about clone sizes, number of clones within stands, 261 clonal boundaries, and frequency of sexual reproduction. The ability to precisely define current clonal

262 boundaries both above and below ground is helping managers to understand how clones become 263 established and spread in a landscape. Mutation accumulation can even be used in some circumstances to 264 estimate clonal ages (Ally et al., 2010). Scientists are using genetic tools to determine ploidy levels 265 (numbers of chromosome copies) in aspen. These levels may be linked to physiological and phytochemical differences (See Lindroth and St. Clair, this volume), and used to describe patterns of

267 range-wide genetic diversity and historical range expansions and contractions. Rapidly emerging

268 technological advances in genetic analysis also offer exciting possibilities for understanding adaptive

269 variation, responses to climate change, and ecological tradeoffs in aspen. In order to connect the potential

270 of these genetic tools to aspen management issues, increased communication will be needed between

271 geneticists and forest practitioners. Mock et al, (this volume) present a review for non-geneticists of 272 current and emerging genetic tools, with applications for aspen ecology and management.

\section{3. Future Directions} realization of unique aspen "types." The papers herein comprise an attempt to communicate this vital

278 message via a number of disciplinary experts. Ongoing investigations into cover change, disturbance and 
chemical ecology, ungulate herbivory and wildlife uses, genetics, and changing climates contain a common thread emphasizing this diversity. We believe consideration of these advancements will better inform managers toward more appropriate aspen prescriptions. findings of previous aspen symposia (e.g., Shepperd et al., 2001) to help guide future aspen work: 1)

284 consideration of multiple disturbances and their interactive effects; 2) the need for further clarity among 285 scientists on exactly what constitutes aspen "decline" (e.g., are there specific spatial, temporal,

286 physiological requirements?); 3) herbivory can reduce community resilience and significantly alter future 287 aspen cover; 4) unraveling and managing herbivore impacts demands interdisciplinary approaches using 288 plant physiology (i.e., defense and growth), wildlife biology and behavior, aspen ecology, and the social 289 sciences; and 5) there is greater genotypic complexity than previously thought in these landscapes and we 290 are only beginning to understand the ecological ramifications of this diversity. For instance, where management often takes place at the "stand" level—a term admittedly fraught with ambiguity—western aspen stands should not automatically be thought of as individual clones. High genetic variation in aspen underlies a wide-ranging phenotypic diversity (St.Clair et al., 2010) that influences plant community 294 characteristics and ecosystem processes. Beyond key messages, we found numerous instances of research questions that would benefit

296 from multi-disciplinary analyses. For example, participants at the symposium felt that the combination of 297 changing climates, altered disturbance patterns, and intensive herbivory is placing aspen in a potentially 298 non-resilient situation. From this starting point alone, a number of exploratory avenues arise: this vary at stand, landscape, and regional scales, and with increasing animal populations? 
b) Can historical range of variability, determined via written accounts and anthropological methods, be a useful means of establishing wild ungulate targets today?

c) Is "carrying capacity" a useful precept for browsing ungulates? Can aspen recruitment be used as an indicator of success (or failure) of carrying capacity?

d) Can large disturbances producing large-scale regeneration overwhelm ungulate herbivory?

e) Do apex predators, such as wolves, have the same cascading impacts on all aspen environments (i.e., with varying prey numbers, disturbance intensities, aspen densities)? If not, what factors are most important in explaining variation?

314 Interdisciplinary work — via hypothesis generation, field, and laboratory research—using 315 wildlife, forest, physiological, geographic, and molecular ecologists will increasingly be 316 required. Effective investigation of these questions, and like inquiries on other aspen topics, will 317 increasingly require collaboration across institutions and disciplines.

318 We acknowledge that some topics were excluded from the "Resilience in aspen..." symposium, 319 due to space and time limitations. Topics such as linking aspen conditions (and change) to species 320 diversity, exploration of niche theory as related to future climates, water use and storage in altered 321 communities, soil properties and carbon accumulation, and various socio-economic issues all deserve 322 greater attention. We believe these topics are not only important in their own right, but may be useful as 323 interdisciplinary links with subject areas discussed here. Thus, we encourage continued inclusion of 324 multidisciplinary approaches via these and other (unmentioned) aspen-related topics in future forums. Finally, this gathering of aspen investigators felt that we should engage the social sciences to a greater degree in aspen problem-solving. Social, cultural, and economic decision-making underlies many 
ecological issues surrounding aspen science and management, yet we have little sound information

328 regarding how and why people act in this arena. For instance, in many western states and provinces wild

329 game management is driven by hunter license fees. Increased hunting (and fees) often leads to greater

330 herbivore numbers, which in turn directly impacts aspen survivorship. How can science improve these

331 socio-economic mechanisms so they mesh with positive ecological outcomes? It became clear to

332 attendees at the "Resilience in aspen ..." symposium, as it should be to most readers, that human

333 activities ultimately drive many of the ecological issues we face. Applied research in this area is clearly

334 lacking. There are probably many reasons for this, but we would be remiss if we didn't point out the vital

335 need for better collaboration in bridging ecological and social research endeavors related to aspen

336 sustainability. One glaring avenue in need of strong social context is effective communication of findings

337 to a variety of audiences. In the end, clear messages from the science community, in both academic and

338 public spheres, provide the most promise for aspen's long-term resilience. Toward that end, articles in

339 this Special Issue of Forest Ecology and Management invite readers to reconsider existing paradigms in

340 aspen ecology, inspire collaborative work in the areas in which we have identified knowledge gaps, and

341 facilitate clearer and more effective communication of aspen conservation science to a wider audience.

343 Acknowledgements:

The High Lonesome Ranch, De Beque, Colorado, played an instrumental role in organizing and

346 hosting "Resilience in Aspen: restoring ecosystem processes through applied science." The American

347 Forest Foundation, High Lonesome Ranch, Brigham Young University, U.S. Bureau of Land

348 Management, and Utah State University's Western Aspen Alliance co-sponsored this event with generous

349 donations of funds and time. In addition to authors and presenters of materials at this symposium, we are

350 grateful to additional participants from universities, management agencies, and conservation

351 organizations for their generous and insightful input to these deliberations. 


\section{References:}

Ally, D., K. Ritland, and S. P. Otto. 2010. Aging in a long-lived clonal tree. PLOS Biology 8:e1000454.

Bartos, D. L. and R. B. J. Campbell. 1998. Decline of quaking aspen in the Interior West--examples from Utah. Rangelands 20:17-24.

Beck, J. L., J. T. Flinders, D. R. Nelson, C. L. Clyde, H. D. Smith, and P. J. Hardin. 1996. Elk and domestic sheep interactions in a north-central Utah aspen ecosystem. Research-Paper Intermountain-Research-Station,-USDA-Forest-Service:1-114.

Brown, K., A. J. Hansen, R. E. Keane, and L. J. Graumlich. 2006. Complex interactions shaping aspen dynamics in the Greater Yellowstone Ecosystem. Landscape Ecology 21:933-951.

Calder W.J., and S.B. St.Clair. 2012. Facilitation drives mortality patterns on succession gradients of aspen-conifer forests. Ecosphere 3 (6): 57.

DiOrio, A. P., R. Callas, and R. J. Schaefer. 2004. Forty-eight year decline and fragmentation of aspen (Populus tremuloide) in the South Warner Mountains of California. Forest Ecology and Management 206: 307-313.

Fechner, G. H. and J. S. Barrows. 1976. Aspen stands as wildfire fuel breaks. U.S Department of Agriculture. Forest Service, Rocky Mountain Forest and Range Experiment Station:29 pp.

Gallant, A. L., A. J. Hansen, J. S. Councilman, D. K. Monte, and D. W. Betz. 2003. Vegetation dynamics under fire exclusion and logging in a Rocky Mountain watershed, 1856-1996. Ecological Applications 13:385-403.

Hobbs, R. J., and L. F. Huenneke. 1992. Disturbance, diversity, and invasion: Implications for conservation. Conservation Biology 6(3):324-337.

Hogg, E. H., J. P. Brandt, and M. Michaelin. 2008. Impacts of a regional drought on the productivity, dieback, and biomass of Canadian aspen forests. Canadian Journal of Forest Research 38:13731384. 
Jones, B. E., D. F. Lile, and K. W. Tate. 2009. Effect of simulated browsing on aspen regeneration: implications for restoration. Rangeland Ecology and Management 62:557-563.

Kochy, M. and S. D. Wilson. 2001. Nitrogen deposition and forest expansion in the northern Great Plains. Journal-of-Ecology-Oxford 89:807-817.

Kulakowski, D., T. Veblen, T., and S. Drinkwater. 2004. The persistence of quaking aspen (Populus tremuloides) in the Grand Mesa area, Colorado. Ecological Applications 14:1603-1614.

Landres, P. B., P. Morgan, and F. J. Swanson. 1999. Overview of the use of natural variability concepts in mangeing ecological systems. Ecological Applications 9:1179-1188.

Landhäuser, S.L., D. Deshaies, and V.J. Lieffers. 2010. Disturbance facilitates rapid range expansion of aspen into higher elevations of the Rocky Mountains under a warming climate. Journal of Biogeography 37:68-76.

Martin, T.E.; Maron, J.L. 2012. Climate impacts on bird and plant communities from altered animal-plant interactions. Nature Climate Change 2: 195-200.

Manier, D. J. and R. D. Laven. 2002. Changes in landscape patterns associated with the persistence of aspen (Populus tremuloides Michx.) on the western slope of the Rocky Mountains, Colorado. Forest Ecology and Management 167:263-284.

Millar, C.I.; Stephenson, N.L.; Stephens, S.L. 2007. Climate change and forests of the future: managaging in the face of uncertainty. Ecological Applications 17:2145-2151.

Mock, K. E., R. C.A., M. B. Hooten, J. Dewoody, and V. D. Hipkins. 2008. Clonal dynamics in western North American aspen (Populus tremuloides). Molecular Ecology 17:4827-4844.

Rehfeldt, G. E., D. E. Ferguson, and N. L. Crookston. 2009. Aspen, climate, and sudden decline in western USA. Forest Ecology and Management 258:2353-2364.

Ripple, W. J., E. J. Larsen, R. A. Renkin, and D. W. Smith. 2001. Trophic cascades among wolves, elk and aspen on Yellowstone National Park's northern range. Biological Conservation 102:227-234.

Rogers, P. C., R. Rosentreter, and R. Ryel. 2007. Aspen indicator species in lichen communities in the Bear River Range of Idaho and Utah. Evansia 24:34-41. 
404 Rogers, P.C.; Landh $\square$ user, S.M; Pino, B.; Ryel, R.J. 2012. Functional Classification and Management of Western North American Aspen (Populus tremuloides Michx.). Forest Science (In Review).

406 Sankey, T. T. 2009. Regional assessment of aspen change and spatial variability on decadal time scales.

$407 \quad$ Remote Sensing 1:896-914.

408 Shepperd, W.D.; Binkley, D.; Bartos, D. L.; Stohlgren, T. J. and Eskew, L. G. 2001. Sustaining aspen in 409 western landscapes: symposium proceedings. USDA, Forest Service, Rocky Mountain Research 410 Station, RMRS-P-18, June 13-15, 2000, Grand Junction, Colorado. 460 p.

411 St.Clair, S.B., Mock K., Lamalfa E., Campbell R. and R. Ryel. 2010. Genetic contributions to phenotypic 412 variation in physiology, growth and vigor of aspen (Populus tremuloides) clones.

$413 \quad$ Forest Science 56: 222-230.

414 Wooley, S. C., S. Walker, J. Vernon, and R. L. Lindroth. 2008. Aspen decline, aspen chemistry, and elk 415 herbivory: are they linked? Rangelands 30:17-21.

416 Zier, J. L. and W. L. Baker. 2006. A century of vegetation change in the San Juan Mountains, Colorado: An analysis using repeat photography. Forest Ecology and Management 228:251-262. 